Article

\title{
The relational navigator: a pedagogical reframing of widening educational participation for care-experienced young people
}

\author{
Penny Jane Burke, ${ }^{1, *(1)}$ Claire Cameron, ${ }^{2}$ (D) Emily Fuller $_{,}{ }^{1}$ Katie Hollingworth ${ }^{2}$ \\ ${ }^{1}$ Centre of Excellence for Equity in Higher Education (CEEHE), University of Newcastle, \\ Callaghan, NSW 2308, Australia \\ 2 Thomas Coram Research Unit, UCL Institute of Education, London WC1E 6BT, UK \\ * Correspondence: pennyjane.burke@newcastle.edu.au
}

Submission date: 2 August 2021; Acceptance date: 11 October 2021; Publication date: 25 November 2021

\section{How to cite}

Burke, P. J., Cameron, C., Fuller, E. and Hollingworth, K. (2021). The relational navigator: a pedagogical reframing of widening educational participation for care-experienced young people. International Journal of Social Pedagogy, 10(1): 15.

DOI: https://doi.org/10.14324/111.444.ijsp.2021.v10.x.015.

\section{Peer review}

This article has been peer-reviewed through the journal's standard double-blind peer review, where both the reviewers and authors are anonymised during review.

\section{Copyright}

2021, Penny Jane Burke, Claire Cameron, Emily Fuller and Katie Hollingworth. This is an open-access article distributed under the terms of the Creative Commons Attribution Licence (CC BY) 4.0 https://creativecommons.org/licenses/by/4.0/, which permits unrestricted use, distribution and reproduction in any medium, provided the original author and source are credited • DOI: https://doi.org/10.14324/111.444.ijsp.2021.v10.x.015.

\section{Open access}

International Journal of Social Pedagogy is a peer-reviewed open-access journal.

\begin{abstract}
Young people in state care not only lose support, usually at 18 years of age, but also experience unequal participation in post-secondary education. This has raised concern about the importance of widening participation (WP) for care-experienced young people (CEYP). However, CEYP are often institutionally stigmatised and this could be worsened by WP interventions that are framed by deficit discourses. Weaving together social pedagogies and social justice theories, the article aims to reframe WP away from deficit discourses through recognition of the systemic, structural and cultural inequalities that most CEYP must navigate to access formal education. We introduce the concept of the relational navigator, in which a pedagogical relationship enables the navigator to 'pilot' through complex systems and transitional processes in collaboration with, and through
\end{abstract}




\begin{abstract}
'walking alongside', the CEYP with respect to their lived contexts and experiences. This article draws from the reflections of WP navigators situated in two small-scale WP projects, one in an English museum and the other in an Australian university. Our analysis of the reflections of the WP project navigators is offered as a preliminary exploration of the potential the relational navigator as a way to shift deficit discourses and work towards a reframing of WP through a social pedagogical perspective.
\end{abstract}

Keywords care-experienced young people; relational navigator; widening participation; social pedagogies; social justice

\title{
Introduction
}

In most jurisdictions, support for young people in state care evaporates when they reach 18 years of age (Cameron, Hauari and Arisi, 2018). In population-based studies in Finland, Germany and Britain, young adults who have ever been in out-of-home care have elevated risks of poverty, lower levels of education and employment and higher levels of mental health difficulties at the age of 30 relative to their age cohort who have never been in care (Cameron et al., 2018). Ongoing disadvantage reflects an impoverished and often abusive birth family context, a child welfare system that insufficiently compensates for early difficulties and institutional stigmatisation, or misrecognition (Fraser, 1997), that often leads to the exclusion of care-experienced young people (CEYP) ${ }^{1}$ from educational opportunities.

Key life opportunities, such as accessing higher education (HE), are not reaching CEYP to the same extent as their peers (Harrison, 2018; McDowall, 2009), and widening participation (WP) ${ }^{2}$ policies are unevenly developed across countries (Cameron et al., 2018). In Australia, care experience is not explicitly recognised in WP policy (Harvey, Andrewartha and McNamara, 2015). England has legislation and policy to support CEYP to attend university, but implementation is uneven and under-resourced (Boddy, Bakketeig and Østergaard, 2019) and the rate of early withdrawal is twice that of their peers (Harrison, 2018). The legislative and policy environment in England is relatively supportive of CEYP, but only 6 per cent begin HE at around the age of 19 (DfE, 2019). By the age of 23, the rate of HE access is estimated at 12 per cent (Harrison, 2019). This represents around one-third of the access rate of young people who have not been in care (43 per cent; Harrison, 2019). Those who access HE have generally overcome substantial hurdles associated with partial school attendance, changes of foster or residential care arrangements, elevated mental health difficulties, continuing and often fraught relations with birth family and wider kin and bereavement (Jackson and Cameron, 2014). Those who complete their undergraduate degrees tend to have continuing support from a key adult figure, such as a foster carer or personal advisor (Jackson and Cameron, 2014).

Australian national and state inquiries into the unequal outcomes of children and young people from care-leaving backgrounds illuminate the significance of focusing on this group for WP (McHugh and Pell, 2013; Raman, Reynolds and Khan, 2011; Sammut, 2011). In both Australia and the UK, the framework of the 'relational navigator', underpinned by social pedagogic and social justice principles, is novel as a WP strategy. In England, WP policy measures to support CEYP include the appointment of a senior officer in each local authority to monitor progress and provide resources (called a Virtual School Head), local monitoring through a school-based 'designated teacher', financial support such as HE bursaries and the inclusion of the specific category of CEYP within broader, university-based WP initiatives. Yet despite the policy and resources dedicated, the proportion of care-experienced students (CES) has not significantly improved. This has mainly been explained in relation to lower school qualifications and the higher incidence of special educational needs among CEYP relative to their age group (Harrison, 2019). However, it is important to locate such explanations in wider structural and systematic inequalities to avoid deficit misframings of WP (Burke, 2002).

Deficit discourse framing of WP has been extensively critiqued (e.g. Burke, 2002, 2012; Williams, 1997) for its primary focus on the perceived deficiencies of disadvantaged groups and the reduction of targeted individuals to narrow, and often harmful, policy categorisations. We argue that deficit discourses do harm by pathologising CEYP and by erasing from view the significant structural, systemic and cultural inequalities CEYP face. Deficit discourses constrain WP practice often in relation to a 
construction of support in largely remedial, generic and decontextualised terms. Power relations are not considered in such WP frameworks and the young person is constructed largely through the lens of deficiency, with support offered as a means to 'fix' or 'correct' the individualised 'problem'. In contrast, a relational, social pedagogical reframing of WP understands disadvantage as produced through multidimensional social injustices, including maldistribution, misrecognition and misrepresentation (Fraser, 1997, 2003). In reframing WP through a social pedagogical and social justice lens, processes of mutual critical consciousness are prioritised, with the intention to transform relations of power (Nixon, Misiaszek and Burke, 2015). This is in stark contrast to WP policy, which aims to 'include those who are excluded into the dominant framework/state of being, rather than challenging existing inequalities within the mainstream system, or encouraging alternative ways of being' (Archer, 2003, p. 23). Rather, WP practice through a relational navigator approach aims to (re)position the young person as an active participant, redistribute resources and opportunities, recognise and value the young person's experiences, perspectives and contexts, and enable the young person to represent their interests and concerns (Cammarota, 2007).

We argue that a new approach to WP practice is needed that shifts from deficit to relational frameworks. Aiming to recognise the social location of CEYP, we bring together the insights of social justice principles and social pedagogies to introduce the concept of the relational navigator. Drawing on case examples from two CEYP-focused WP programmes, we explore the relational navigator as a way of resituating WP practice away from deficit discourses and towards working alongside young people.

\section{The relational navigator}

The concept of navigation is most used in the sense of 'finding one's way' as agentic individuals. For example, Boddy et al. (2019) described CEYP in Denmark, Norway and England described as 'navigating precarious times', including transitions to new ways of living, everyday life and complex state and informal arrangements for support in order to survive, or, ideally, live well. The term navigator has been adopted within some health services to refer to a 'linch pin or enabler' who provides assistance to find one's way around complex systems and overcome barriers to treatment (HEE, 2016, p. 6). This essentially customer service-provider framework neglects the relational and pedagogic dimensions with which we are concerned.

Our relational navigator is fundamentally a pedagogical encounter, in which the navigator and young person learn together. This draws from notions of peer mentoring present in both the field of social care and education (Garcia-Molsosa, Collet-Sabé and Montserrat, 2019) and the social pedagogic concept of the 'common third' where the activity or 'third' forms a focus for mutual curiosity and learning between mentor and mentee (or worker and young person) (Cameron, Connelly and Jackson, 2015). We see navigation as scanning the horizon and making sense of possibilities and futures, and the meshing of possibilities for action in the here and now on the basis of accompanying young people through interpersonal encounters that are initiated by practitioners and worked through on the basis of mutuality and solidarity.

The relational navigator (RN) recognises the socially contextualised positionings of navigator and young person. The RN aims to 'pilot' through complex systems and transitional processes in collaboration with, and through 'walking alongside', the young person, with respect to their lived contexts and experiences. This emphasis on developing critically reflexive orientations enables the $\mathrm{RN}$ to critically consider the institutional power relations and inequalities that inevitably play out in the pedagogical relationship and that then shape practice. Drawing from Freire (1970), this supports pedagogic praxis; keeping critical reflection and action in ongoing dialogue (Burke, 2012). In keeping with social justice perspectives, a sense of belonging is fostered through the recognition of a person's value, not only in the individual skills and competencies that she develops, but also in her capacity to participate as a fully recognised member of the community to which she is part.

\section{The two programmes}

We discuss two small-scale programmes, one in an Australian university and one located in a museum in England, to further explore the concept of relational navigator and its potential for reframing WP support. We analysed the reflections of the practitioners in each project as our main method for 
considering the possibilities and challenges of an RN reframing of WP practice. The two programmes were complementary but not identical; we are not seeking to compare them but to find similarities rather than differences as a basis for developing the concept of relational navigator.

\section{Tracing our Tales programme and data - The Foundling Museum, London}

Tracing our Tales (ToT) is a creative mentoring programme that equips CEYP to be artists' assistants. In recognition of their childhood difficulties in education, and life more generally, the programme also aims to enhance employment and life skills. The programme lasts approximately six months and is run by a freelance artist, $A$, and the museum's curator of artists' projects, $E$ (hereafter referred to as $\mathrm{E}$ and $\mathrm{A}$ ). Trainees (hereafter known as participants) ${ }^{3}$ are recruited via local authorities' leaving care teams and agencies responsible for vocational training. Applicants are selected via interview for their motivation and ability to commit to the programme, and they are paid a nominal amount for each day of participation. Participants assist with running workshops with members of the public, including children, who learn about the museum and its exhibits. The museum's purpose is to tell the story of the first foundling hospital in the UK; as such, the lives of the people who lived there as children and the lives of the CEYP today share some common ground.

The ToT evaluation consisted of: researcher attendance at multiple training sessions for each of three annual cohorts to observe the pedagogic process and become familiar with the participants; short interviews with each participant at the beginning and longer interviews at the end of each annual cycle; attendance at a sample of workshops held; and interviews with referring agencies. Initial evaluative evidence from participants suggested that both the place (i.e. the museum and its history) and the pedagogical approaches of the WP practitioners facilitating the programme (i.e. E and A) were contributing to the participants' reports of improved confidence, and competence, in art and in managing their lives. In response to this finding, Katie Hollingworth carried out an extended interview at the end of the second cohort, where $E$ and $A$ were asked to reflect on the programme's aims, how they had changed in response to the experience of running the programme and their educative approach. This interview is the material on which we draw in this article to outline some of the characteristics we describe as a 'relational navigator'.

\section{Live, Learn, Grow programme and data - Centre of Excellence for Equity in Higher Education (CEEHE), University of Newcastle, New South Wales}

Live, Learn, Grow (LLG) is a university-based programme developed with two key aims: to walk alongside and support CES as they navigate complex university systems; and to support school-aged CEYP to transition on to HE. The methodology emerged from strength-based, solution-focused perspectives (Malekoff, Salmon and Steinberg, 2014) and through its development has been reframed by social justice praxis, with a focus on building meaningful and sustainable relationships within and across two fields of practice (WP practice within universities and service-sector care within care agencies). The current iteration of LLG is situated within a collaborative praxis-oriented space (the CEEHE), bringing critical theory and practice in dialogic conversation, in which a key aim is to work with students within a multidimensional social justice framework of redistribution (of resources, networks and opportunities), recognition (of the experiences and identities of young people) and representation (of diverse perspectives across fields of practice, most importantly of the young people themselves).

We used a conversational interview method between Penny Jane Burke and Emily Fuller to explore LLG practice, drawing on Emily's critical reflections of developing the programme. Employing the 'autobiography of the question' method (Burke, 2002; Burke and Gyamera, 2020; Miller, 1995), the first stage involved reflective writing produced by Emily and shared with Penny, followed by an in-depth recorded conversational interview facilitated by Penny with Emily. The aim of these reflections, within the context of auto/biographical and auto/ethnographic approaches, was to interrogate the 'insider' perspectives in conversation with a wider research team outside of LLG (Claire Cameron and Katie Hollingworth) in order to further articulate and problematise its social justice principles.

The themes explored in the article are the result of an analysis of the two interviews, developed by Claire and Penny through a detailed coding framework and the selection of central thematic areas to explore key features of the relational navigator. The analysis was guided by the insights of social pedagogies and social justice. These themes are (i) engagement through creating both meaningful 
connections and challenges and (ii) expectations in the context of deficit discourses. We then discuss the promise of the relational navigator concept through the themes of relationality, recognition and walking alongside one another.

\section{Creating meaningful connections with participants' own lives and biographies}

Developing meaningful connections emerged as a key theme in the reflections of both programmes. In ToT, the young people were explicitly selected because of the common ground between their own biography in care and that of the museum's story about being the UK's first foundling hospital: 'the story of the museum helps ... so you can do something fantastic at the British Museum but ... they're never going to have that automatic link with the story' (E and $A)$.

This created an immediate and meaningful connection as the programme participants embodied the museum's reason for being. E and A were concerned to create an environment in which the young people felt very welcome by everyone from the receptionist to the CEO: 'the staff also help because they are warm and welcoming and they all know them'.

This was linked to:

[the] way that we run it, very early on they feel at home here and I think that's something quite different ... we really try and do, to create this safe space for them to be themselves ... what we try and do is say well, you know you're not crap at this in this place; you're really [a] valued member of this museum, cos it's about you. (E and A)

The structure of the programme allowed for visits and some of these supported finding out more about the museum, its history and the lives of other people who had been in care. The visit of a former foundling where the participants asked questions about his life was 'one of the main things [the young people] engaged with, they loved it, at the end I said to them what was your best thing and $100 \%$ said seeing $\mathrm{J}$... [they had so much in common with him]' (E and A). Visiting the Foundling Hospital Archive and hosting a visit from poet and Foundling Museum trustee Lemn Sissay cemented connections between the museum and the participants. A visit from a group of young people seeking asylum that was planned around a ceremony of solidarity and a tour of the museum helped the participants make meaningful connections both with the visitors and with themselves as part of the museum's story. The ceremony involved greetings in their own languages, a guided tour in pairs of visitor and participant, and photographing the two beside works of art so 'basically the asylum seekers were part of the museum' (E and A).

Further connections were made by asking both the young people seeking asylum and other participants to arrive with an object that 'meant something to them' and 'so they scanned their things and that was quite touching' ( $E$ and $A)$.

The careful planning of the event, and use of symbolic activities, among two groups of young people who did not speak the same language, aimed to enable a sense of shared biographies of geographic and familial dislocation and shared identity in the space and story of the museum. The curator summed up the impact of the visit:

What was wonderful was ... this group of asylum seekers who didn't speak any English who
obviously their story and their whole background and experience totally relates to the story
of the foundling hospital, they were ... greeted by ... care leavers that also had connections
with the story and they ... welcomed them and one of the things that [the person] who runs
the project said to me afterwards, she said that she couldn't believe how welcomed they felt
$\ldots$ and for once the trainees absolutely rose, it was electric. (E and A)

However, in order to avoid misrecognition through unwittingly producing an individualistic and/or deficit construction of the young people, E and A did not focus attention on the participants' individual biographies. While connections were made with the museum's story, 'it's really important ... that you don't do too much of that because ... the project is not about that ... We never talk about their lives, they can bring it up if they want to but if there's a reason then we sort of focus it' (E and A). In the LLG programme, students were offered opportunities to meet each other through working at events put on by CEEHE to which they were affiliated, or through an informal CEEHE research project, 
there are some students who have been working quite closely together for a year and a half now. They have gotten to know each other and will kind of check in on each other ... I've provided opportunities for other students to meet, offering to introduce them and allow them to choose what happens after that. But most students haven't wanted to take that up. The response has often been, 'I don't want to be defined by that, and to just hang out with other care leaver students. I'd rather meet new friends and do my own thing.' (EF)

This respectful navigation of the biographical connections and differences between students also provided enough structure to facilitate processes of transition into a new environment. The LLG programme had a clear aim to recognise a feeling of disorientation that often accompanies embarking on university study: 'for a lot of the students I work with, they may come into uni feeling a bit out of place, a bit unsure of if it's something that they can do or somewhere they should be' (EF).

The LLG programme aims to 'normalise' the experiences of CES through making a meaningful link between them and the rest of their cohort:

Having someone there who they know a bit and trust when they say, 'It's not just you, everyone has this problem. This is a normal thing. This is something that a lot of people have difficulty with. This is a clunky system or this is just how it is', can make a huge difference. (EF)

EF explained that her pedagogical approach was 'not ... to direct people or make decisions ... It's just about being there while they're deciding what they're doing and figuring things out. It is being alongside, rather than being in front and leading things.'

Being alongside a CES, and providing resources and strategies to enable students to navigate challenging HE systems on the basis of mutuality, has strong resonance with a social pedagogical approach (Eichsteller and Holthoff, 2011). Social pedagogy conceptualises the target population of a service, in this case CES, as inherently competent, and the provider of a service, in this case a 'navigator', as inhabiting a moral universe, in which there are ethical obligations towards the person being supported. Social pedagogues are aware of their 'Haltung' or mindset and ethos, and their responses are congruent with this. Haltung expresses an emotional connectedness to the people with whom they work and a 'profound respect for human dignity' (Eichsteller and Holthoff, 2011, p. 36). Relatedly, social pedagogy understands human action in its social context and from the standpoint that children and adults are experts in their own lives (Langsted, 1994). Pedagogical engagement in this context relies on knowing and respecting the individual's existing knowledge and absences of knowledge and finding ways to bring new learning to life.

\section{Creating challenges to participants' established lives - pushing boundaries}

The second method of pedagogical engagement emerging in the reflections was to create challenges and push boundaries in how the participants were developing new forms of knowledge, skill and understanding about themselves. ToT was explicitly skills focused, and aimed at young people with dislocations in their educational trajectories to date. Programme facilitators articulated a strong need for 'structure and ... lots of change, it needs to have variety and pace' as 'just making a piece of art isn't enough for them' (E and A).

The basic structure of the programme, attending for set hours on one day a week, with participants paid a nominal amount for attendance, was established as a baseline and considered by the programme as a prerequisite for subsequent employment. Time and timekeeping was a challenge for participants:

last year because ... they were so slow and we had ... people coming and not coming and then having to repeat certain things, with the others because it was skill based and they had to have these [skills] to be able to do the workshops so we were really sort of loooooong period ... that was one thing that for us was just too much, for them it was ok but for us it was a bit too much and this year it's been a lot more snappy. ( $E$ and $A$ )

Further, the art skills themselves were challenging: 'once they're engaged in doing the art skills ... they ... really love it, like when they're learning the casting, [but] they have short attention spans, we have to move on quite quickly.' 
As preparation for leading tours, and assisting with art workshops, much effort went into learning public speaking. Central to this was the aim to develop participants' self-confidence. A introduced art games to support the building of trust seen as essential to self-expression:

one of the things that really works are the art games, they love it ... they're not random games and [participants have] learnt now that they're inspired by artists who do similar, you know they're, 'that's cracking, that's amazing', that gets them all engaged and they come with all this baggage but in 5 minutes they're all screaming and laughing cos we're all throwing balls at each other!

Gaining self-confidence and knowledge through social interactions that present challenges (what Vygotsky (1978) would call the 'zone of proximal development'), participants were able to act as experts on the museum's story and content during public events and workshops: 'When they've gone to the private views ... that's like gold dust, they are so special ... I just went, "Oh go, say nice things please!" And they did' (E and A). E went on to say: 'I would be quite confident about them giving a talk in the collection ... it would be a talk using their experiences, J's [alumni] experiences, all the people that they met [on the programme].'

A key pedagogical element in creating challenge was building towards critical moments in the programme. This creates '[a sense of] purpose for us ... otherwise it would have been like "why are we doing printing" ... so having key moments where they can ... show off their skills and purposefully meeting someone or going on a trip like the archive, but again it has to be very carefully chosen' (E and A)

In the LLG programme, pushing boundaries occurred both in relation to working with students and working at the interface of CES and other agencies. Where participants were living on campus, EF found it difficult 'seeing students getting caught up in systems and things happening within the university that I'm trying to help them navigate through, when I don't necessarily agree with or understand the purpose of them myself'. Moreover, 'almost all of the students I was working with found that lliving next to students from very different backgrounds] hard right from the beginning. They felt they didn't fit very well with the other residents' (EF). Her role was to navigate the two worlds and support CES to find a meaningful and valued existence alongside other students with whom they might share little. In addition, there were challenges from how some staff within the university reacted to CES:

Sometimes when staff know who students are, they were sometimes hyper-alert to any potential cause for concern. So, I was spending a lot of my time just asking, 'If this was any other student, would we be having this conversation? Would this be a thing that had been flagged?' And trying to approach that conversation carefully, because I also didn't want to cause tension and create extra problems. (EF)

This was

quite challenging, and ... has actually impacted how I've worked within the university. I've always been careful about protecting the student's confidentiality anyway, but ... I have to really stop and think how much I want to talk [to colleagues] about what I'm doing, in case I accidentally identify students somehow. (EF)

Working between the expected 'sameness' of a student status as living on campus and the potential misrecognition of CES students inadvertently led to diminished institutional visibility for the LLG programme.

In relation to other agencies, EF had to both reassure and challenge colleagues in the care sector,

because there is a legitimate concern from agency staff about students going to uni because they are navigating so much when they leave care. So, this is just adding another thing to their plate, right when they may have lost the support of being in care. They don't have the financial support, they don't have carers, so there is that concern of, 'Well, how are they going to cope?'

EF found that, in addressing this institutionalised lack of confidence in (or misrecognition of) CEYP, the contribution of young people had been vital: 


\begin{abstract}
Sometimes it's as simple as letting people know that enabling programmes and alternate pathways exist, so that they know there is a way to get to university, and could consider it. But sometimes it requires challenging some of those ideas about who can and should go to uni, and that's where the students have actually been really key as well ... they'll come to events, and some of them are the young people who no one thought would or could go to university, and they talk about that. They'll say, 'Yep, I didn't finish year 12, I didn't do any of the things that people think you should do, and yet here I am at uni, and this is how it worked for me.' I think that has been really key, having the actual students involved, because I can say it over and over again, but it's very different to actually have the person who went through it say it.
\end{abstract}

The pedagogical strategies of both programmes aimed to engage CEYP and enable them to navigate challenging and sometimes discriminatory educational institutions and pathways through micro-steps of pacing, games, time discipline, building momentum and excitement, social interactions that build new skills, but also wider steps of advocacy and reframing expectations of them to professionals in other agencies. However, the relational navigator strategy was more explicit in the LLG programme due to its location in a research centre framed by social justice theories and pedagogies. Both programmes aimed to enable young people who have experienced systemic forms of marginalisation to participate in mainstream educational institutions through working alongside them and building their skills and confidence, echoing the commitments of social pedagogy. German educational theorists such as Herman Nohl (1879-1960) argued that helping people to learn and grow in themselves required an understanding of their social context and how they uniquely interact with their social context (Eichsteller and Holthoff, 2011). Challenging institutionalised 'misrecognition' of young people by reframing the ways CEYP are seen in relation to educational capability is underpinned by pedagogies that explicitly aim to redress unequal relations of power (Freire, 1970).

\title{
Expectations and self-reflexivity
}

Expectations are generated socially, institutionally and discursively and in relation to normative perspectives that shape identity constructions of young people and their perceived potential and capability to benefit from lifelong learning and HE (Burke, 2012; Burke and Jackson, 2007). With this understanding of the social, discursive and subjective framings of expectation, which often exacerbate unequal power relations and negative constructions of CEYP, the relational navigator is positioned to interrogate the different expectations that open up and/or limit young people's participation. In order to challenge the deficit frameworks surrounding WP, the relational navigator holds promise to develop a self-reflexive process in her work with others, including staff in social and care work and HE as well as young people themselves. For example, EF engages in processes of self-examination, which helps her to develop mutually empathetic relationships with the young people, explaining that:

I always say that I'm here as someone who has a degree, and works within a university, and I still find it difficult to keep on top of those things and understand them. So how could l expect someone who is trying to figure out this completely new system on top of negotiating living independently for the first time and everything else that they're managing, to just be able to know it all themselves?

EF emphasises the 'importance of those relationships, so working on that and figuring out how to build and manage the relationships'. She expresses this in relation to the expectations she has on herself, which also requires examination of the wider discourses of 'success' at play in HE that shape expectations of students:

It has been important for me to be willing to step back a little bit when needed as well and not take control. There were times where I ... felt that it was my job to make sure the students did well academically and I had to overcome that. So, for example, when students have said 'No, I've tried uni and it's not for me. I've decided I want to do something else, I've had to learn and accept that that can be a good thing, and it doesn't mean I've failed or done a bad job. Not that I ever felt the students had failed, because I've always wanted them to make the best decision for them, but I still had to get past my own worries that maybe if I'd done a better job they would want to stay. 
Self-reflexivity enables the navigators to focus on building relationships of trust, care and compassion, countering institutionalised forms of misrecognition:

We two arrive and say for this day here we'll be something to you, we're going to believe in you, we are going to trust you, we are going to give you confidence, you know it's shared, we actually want you to do well in life, do this course cos we want you. ( $E$ and $A$ )

This relationship building in a particular time and space creates emotional boundaries around the expectations of both participants and navigators: 'What we try and do is say "well you know you're not crap at this in this place; you're [a] really valued member of this museum, cos it's about you"' (E and A). This exchange brings to the fore some otherwise concealed dimensions of the mainstream navigator role, which are built on more conventional power relations between professional/teacher agent and client/student recipient of the 'delivery' of a service. The relational navigator is located within a humanising framework built on social justice principles of trust, care and recognition of CEYP. However, what $\mathrm{E}$ and $\mathrm{A}$ are articulating is that through this intentional effort to (re)position their relationship with the young people through a reframing of WP, something new emerged for them that was unexpected. They experienced joy and fondness, which created a new mode of relationality that seemed to come as a surprise, expressed through a question: 'we're really fond of them, aren't we?'

In the university context, the relational navigator is enabled to be more attentive to unequal relations of power and to explicitly challenge stigmatising constructions of CES. EF explains:

I am cautious of how I talk about ... some of the difficulties faced by care leavers, because I don't want the students I'm working with to be labelled with this assumption that 'they're part of a support programme and they've been in out-of-home care, so if they're having a bad day it must mean something huge is going on and we need to be worried'. The students are still normal 18-, 19-, 20-year-olds, and sometimes they're just going to have a bad day.

EF alludes to the complexity of the navigational role, which is in part challenging the expectations that emerge from narrow constructions of success on the part of institution, the students and the programme itself. While clearly the programme wants CES to thrive, the principal means of achieving this is having:

flexibility around expectations, and figuring out the priorities. If the programme was just a push for increased enrolments and good grades, I don't think it would be positive for the students or achieve some of the things it has.

The navigators in our study were proactively working to transform the opportunities of the young people themselves but in a wider context of challenging institutionalised deficit discourses that often undermine WP efforts (Burke, 2012; Williams, 1997). The relational approach recognises that the young people and the navigator are socially positioned within complex power relations in which dominant constructions of capability and success operate to exclude the experiences and identities of marginalised young people through institutionalised forms of misrecognition (Burke, Bennett, Burgess, Gray and Southgate, 2016). The relational approach, in pushing actively against limiting discourses of expectation, strive towards wider transformational processes, in terms of personal and institutionalised expectations.

\section{Relationality, recognition and walking alongside}

The two programmes are not the same and have different pedagogical orientations and contexts. One is more structured and skills based, the other more personalised and focused on accompanying the young person through their HE journey, while simultaneously building broader relationships surrounding and supporting the young person. The idea of accompanying a young person with its connotations of mutuality and support is useful here and has resonances with the French term 'accompagnement', which translates as rather more than providing support, suggesting the idea of 'going alongside' (Boddy and Statham, 2009, p. 8). Boddy and Statham (2009) quote a French manager of a family support service who sought out staff who 'can work with and within the family. [They] need to support and work alongside the family, and above all start where they are at and go at their pace' (p. 8). The central idea is of walking in parallel and guiding at a pace that is acceptable. This is close to the ancient Greek 'pedagogue' to whom sons were entrusted for moral and educative guidance and moved between the family home and the world outside. 
The idea of navigator draws on these concepts of mutuality and guidance, rather than instruction or rigid programming with an implicit assumption of passive reception of information or competences. ToT worked between pedagogical expectations and relational navigation of the internal world of the programme and the external worlds of the CEYP. LLG had less-structured pedagogical expectations, and focused on relational navigation, led by the motivation and perspectives of the CES.

Both programmes recognised the role of physical space, to sediment one's place attachment (Jack, 2010) and to seed belonging through familiarity with the campus or the museum and being able to depend upon knowing what to expect there. The reliability of physical space underpinned the relational navigation. EF explained the relationship between time and space in developing her navigator role. As a graduate who had worked in residential care, this involved taking time to learn about the university spaces (physical and virtual) in anticipation of walking alongside CES:

I have also spent a lot of time, particularly when I first started, just walking around the university looking at different spaces and collecting brochures and other information, as well as looking at just about everything available on the website.

EF pointed to the importance of having both professional and empathetic understanding of the wider context of the young people's lives. In LLG, this required not only building trust to support her relationships with students but also sustaining her relationships with the regional care agencies who have influence in the young people's lives. As a relational navigator, this is not only about transforming the often low expectations of CEYP, but also of developing a relationship of trust with the young people themselves. EF explains:

I don't think there would be any students [here], if we didn't have these relationships with the agencies, because that's how students know about us. I think that also helps us gain a little bit of trust right from the beginning. If a case worker, or someone they know, has introduced them to me and told them about the programme, it helps with building that trust. Now that we've done some work with the agencies, [they] are probably the first person giving that message of, 'This is a thing you can do', to students who maybe haven't considered university. So, that's really key.

ToT also relied on relationships of trust with referring agencies as sources of potential participants, and when navigating between the familiar and unfamiliar in the selection phase, and on occasion when participants asked project leads to contact the agencies (e.g., social workers) on their behalf.

EF's continuing relationship with care agencies provides another ongoing layer of significant support for the young people she is walking alongside:

So, some of these agencies I have relationships with provide that support during the leaving care period ... I can connect students with them and work with them to make sure students have somewhere to live and other external support. And they'll give me advice and feedback. They'll let me know, 'Well, young people leaving care are saying that they're worried about uni because they're worried about cost, or about not having the grades to get in, or ...' So that can help me tailor the support I offer, and what I need to talk about or address when I'm speaking to young people about support available.

Navigators' inherent recognition of participants as individuals of worth was seen as key to growth and development: 'Just having a relationship with someone that believes in you is going to be the starting point of [the young people] growing and developing' (E and A). Connected to this is a strong ethics of care and empathy, seen as key to the navigator's role in offering patient and authentic listening to the young person. EF points out that many of the students might not have anyone else but the navigator to talk to or the topic of concern may only reveal itself with patient listening:

Sometimes it's just about not having anyone else to talk things through with. One student told me recently that they felt I was the only person who cared about them in their first semester ... sometimes you need to be able to sit with it and be patient while they are working things through for themselves. I think patience is really important. Sometimes it's just sitting and listening, even though it might seem quite irrelevant. But then I'll realise that they actually just want to tell me what's happening, and maybe they need me to normalise a certain experience, or reassure them that what they're doing is ok. 
In the context of the accelerated pace of organisational spaces this is particularly salient. The relational navigator affords and values a slower, more patient and empathetic re-orientation to support, in contrast to a highly formalised, transactional approach.

The ToT relational navigator does not carry a supervisory, or legal control or protection responsibility for the young people, but rather involves working between the lines of adult/parent/professional and specialist/artist. This requires a commitment to building confidence through a strong navigation of the delicate relationship boundaries: 'You have to be really confident with these young people, you have to be quite assertive ... and you have to be quite close, not close, open to them and accepting' (E and A). The respectful relationship between the navigator and young people was strengthened by an understanding of the context of their lives and the commitment to supporting their future possibilities:

One of the things that you and I've learnt is that they have this deeply chaotic life and they're very vulnerable, it always really worries me that they can be a victim to many things and they've had many things happen to them in the past. ( $E$ and $A$ )

EF outlined how walking alongside had helped a participant reflect on her achievements and averted a withdrawal from the university altogether:

I also think the relationship and the role have been key for some students who haven't done as well as they would like, to be able to get past that and continue at university, and to eventually do quite well. There's one student I work with who dropped all of her classes halfway through her first semester, failed all of her classes in her second semester, and failed half her classes in her third semester. She almost left university, but we talked about the progress she had made, going from not even finishing a semester to passing two courses, and also about the things she had learnt that could help her going forward. So she kept going, and is now getting Distinctions in all of her classes. That's all down to her working hard, but I don't know that she would have kept going without someone next to her who recognised that hard work, and pointed it out to her, and helped her work through figuring out what she could do next.

\section{Conclusion}

The aim of this article was to outline some defining features of a new way of widening participation for CEYP. We have discussed the potential of the relational navigator in the context of two WP programmes aiming to walk alongside CEYP. The programmes differed in their aims and national contexts, but in both cases the relational dimension of the navigator role shaped the pedagogical strategies. The emphasis of the 'relational navigator' on building ethical and meaningful relationships with young people marks this out from more instrumentally focused navigator roles. Key dimensions of the relational navigator we have highlighted are:

- accompanying or walking alongside young people in a non-hierarchical way

- a Haltung (or mindset) of ethical obligations of respect for, and recognition of, the young person, carried out with care and compassion, where each person is valued and valuable in the here and now and not viewed as their past or an accumulation of risk factors

- supporting young people to navigate unfamiliar demands and expectations, developing new sensibilities of their capabilities and identities

- creating purpose, pace and connection to create meaningful experience and a sense of belonging

- listening with patience and empathy and a willingness to address issues raised

- working between the borders of the individual, the institution and the agencies with whom the young people interact.

The relational navigator has promise for similar WP contexts, broadly defined. It has much in common with the Danish social pedagogue (Cameron, 2004) and with informal youth and community work (Smith and Smith, 2008). It also draws from Freirean forms of pedagogical praxis (Freire, 1970), in which unequal power relations are redressed and reciprocal, iterative processes of critical reflection and action are held in continual conversation (Burke, 2002) and critical reflexivity is a key part of ethical WP practice (Burke, 2012). In both cases, 'caring for' and 'caring about' the young person is foregrounded through an ethics of care, underpinned by social justice principles (Noddings, 2002). In relation to social work, Brandon (1982) positions the person doing the helping as 'ordinary' and 'wholehearted'. Active 
listening is also often considered an essential part of helping others, which involves attending to the other, reflection and probing activities (Culley and Bond, 2004). The relational navigator incorporates the ethos being invoked of democratic, authentic and mutual relations between the parties, within a pedagogical framework of guiding, facilitating and creating the conditions for transformative learning and participation.

\section{Notes}

${ }^{1}$ While we use the abbreviated CEYP to denote children and young people for space reasons, we recognise its use detracts from recognition of the human being behind the acronym.

${ }^{2}$ Widening participation is used here to denote programmes that extend access to education in the broadest sense through provision of training, mentoring and other support mechanisms and is not restricted to access to higher education.

'The term 'trainees' is used by the project but here we have used the term 'participants' to underscore the authors' conceptualisation of young people as active contributors to the overall learning.

\section{Acknowledgements}

We are grateful to the participants in the two projects for sharing their expertise. We acknowledge the support of the Oak Foundation, which funded the evaluation of ToT, and the Australian Commonwealth government who funded the LLG programme.

\section{Declarations and conflict of interests}

Claire Cameron is Editor-in-Chief of International Journal of Social Pedagogy this article is included in; all efforts to sufficiently blind the authors during peer review of this article have been made. The authors declare no further conflicts with this article.

\section{References}

Archer, L. (2003). Race, masculinity and schooling: Muslim boys and education. Buckingham: Open University Press.

Boddy, J., Bakketeig, E., \& Østergaard, J. (2019). Navigating precarious times? The experience of young adults who have been in care in Norway, Denmark and England. Journal of Youth Studies, 23(3), 291-306. [CrossRef]

Boddy, J., \& Statham, J. (2009). European perspectives on social work: Models of education and professional roles. A briefing paper. London: TCRU, Institute of Education supported by Nuffield Foundation.

Brandon, D. (1982). The trick of being ordinary: Notes for volunteers \& students. London: Mind.

Burke, P. J. (2002). Accessing education: Effectively widening participation. Stoke-on-Trent: Trentham Books.

Burke, P. J. (2012). The right to higher education: Beyond widening participation. London: Routledge.

Burke, P. J., Bennett, A., Burgess, C., Gray, K., \& Southgate, E. (2016). Capability, belonging and equity in higher education: Developing inclusive approaches. Newcastle, NSW: University of Newcastle, Australia. Accessed 19 October 2021. https://www.newcastle.edu.au/_data/assets/pdf_file/0011/ 243992/CAPABILITY-ONLINE.pdf.

Burke, P. J., \& Gyamera, G. (2020). Exploring the impact of neoliberalism on female academics in universities: Methods. In Stories from praxis (Occasional Paper 3. ISSN: 2206-4362). Newcastle, NSW: Centre of Excellence for Equity in Higher Education.

Burke, P. J., \& Jackson, S. (2007). Reconceptualising lifelong learning: Feminist interventions. London \& New York: Routledge.

Cameron, C. (2004). Social pedagogy and care: Danish and German practice in young people's residential care. Journal of Social Work, 4(2), 133-51. [CrossRef] 
Cameron, C., Connelly, G., \& Jackson, S. (2015). Educating children and young people in care: Learning placements and caring schools. London: Jessica Kingsley Publishers.

Cameron, C., Hauari, H., \& Arisi, C. (2018). Decent work and social protection for young people leaving care: Gaps and responses in 12 countries worldwide. Accessed 14 October 2021. https://www.sos-childrensvillages.org/getmedia/842a5811-fdb7-41c4-a0b2-45b0e5e79090/ SOS_LeavingCare_web.pdf.

Cammarota, J. (2007). A social justice approach to achievement: Guiding Latina/o students toward educational attainment with a challenging, socially relevant curriculum. Equity \& Excellence in Education, 40(1), 87-96.

Culley, S., \& Bond, T. (2004). Integrative counselling skills in action. London: Sage.

Department for Education. (2019). Outcomes for children looked after by LAs: 31 March 2019. Accessed 14 October 2021. https://assets.publishing.service.gov.uk/government/uploads/system/uploads/ attachment_data/file/884758/CLA_Outcomes_Main_Text_2019.pdf.

Eichsteller, G., \& Holthoff, S. (2011). Conceptual foundations of social pedagogy: A transnational perspective from Germany. In C. Cameron \& P. Moss (Eds.), Social pedagogy and working with children and young people (pp. 33-52). London: Jessica Kingsley Publishers.

Fraser, N. (1997). Justice interruptus: Critical reflections on the 'postsocialist' condition. New York: Routledge.

Fraser, N. (2003). Social justice in the age of identity politics: Redistribution, recognition and participation. In N. Fraser \& A. Honneth (Eds.), Redistribution or recognition? A political-philosophical exchange (pp. 7-109). London and New York: Verso.

Freire, P. (1970). Pedagogy of the oppressed. New York: Continuum [Originally published in 1968].

Garcia-Molsosa, M., Collet-Sabé, J., \& Montserrat, C. (2019). The role of mentoring in the schooling of children in residential care. European Journal of Social Work, 24(1), 47-59. [CrossRef]

Harrison, N. (2018). Using the lens of 'possible selves' to explore access to higher education: A new conceptual model for practice, policy, and research. Social Sciences, 7(10), 209. [CrossRef]

Harrison, N. (2019). Patterns of participation in higher education for care-experienced students in England: Why has there not been more progress? Studies in Higher Education, 45(9), 1986-2000. [CrossRef]

Harvey, A., Andrewartha, L., \& McNamara, P. (2015). A forgotten cohort? Including people from out-of-home care in Australian higher education policy. Australian Journal of Education, 59(2), 182-95. [CrossRef]

HEE (Health Education England). (2016). Care navigation: A competency framework. Accessed 20 October 2020. https://www.hee.nhs.uk/sites/default/files/documents/Care\%20Navigation\% 20Competency\%20Framework_Final.pdf.

Jack, G. (2010). Place matters: The significance of place attachments for children's well-being. The British Journal of Social Work, 40(3), 755-71. [CrossRef]

Jackson, S., \& Cameron, C. (2014). Improving the participation of young people in care in further and higher education: European research and practice. London: Jessica Kingsley Publishers.

Langsted, O. (1994). Looking at quality from the child's perspective. In P. Moss \& A. Pence (Eds.), Valuing quality in early childhood services: New approaches to defining quality (pp. 28-42). London: Paul Chapman.

Malekoff, A., Salmon, R., \& Steinberg, D. M. (Eds.). (2014). Making joyful noise: The art, science, and soul of group work. New York: Routledge.

McDowall, J. J. (2009). CREATE report card 2009. Transitioning from care: Tracking progress. Sydney: CREATE Foundation Limited.

McHugh, M., \& Pell, A. (2013). Reforming the foster care system in Australia: A new model of support, education and payment for foster parents. University of New South Wales. Accessed 19 October 2021. https://learning.berrystreet.org.au/sites/default/files/2018-05/Reforming-theFoster-Care-System-in-Australia_Executive-Summary_0.pdf.

Miller, J. (1995). Trick or treat? The autobiography of the question. English Quarterly, 27(3), 22-6.

Nixon, J., Misiaszek, L. I., \& Burke, P. J. (2015). First Freire: Early writings in social justice education. International Studies in Sociology of Education, 25(2), 150-63. [CrossRef]

Noddings, N. (2002). Starting at home: Caring and social policy. Berkeley: University of California Press.

Raman, S., Reynolds, S., \& Khan, R. (2011). Addressing the well-being of Aboriginal children in out-of-home care: Are we there yet? Journal of Paediatrics and Child Health, 47(11), 806-11. [CrossRef] [PubMed]

Sammut, J. (2011). Do not damage and disturb: On child protection failures and the pressure on out of home care in Australia. Centre for Independent Studies (Australia). Accessed 14 October 2021. https://www.cis.org.au/images/stories/policy-monographs/pm-122.pdf. 
Smith, M., \& Smith, H. (2008). The art of helping others: Being around, being there, being wise. London: Jessica Kingsley Publishers.

Vygotsky, L. S. (1978). Mind in society: The development of higher psychological processes. Cambridge, MA: Harvard University Press.

Williams, J. (1997). Institutional rhetorics and realities. In J. Williams (Ed.), Negotiating access to higher education: The discourse of selectivity and equity. Buckingham: The Society for Research into Higher Education and Open University Press. 